\title{
Las prácticas de evaluación en las materias de ciencias sociales de ESO en la Región de Murcia según la opinión de los inspectores de Educación
}

\section{Assessment practices in the subjects of social sciences in ESO in the Region of Murcia in the opinion of inspectors of schools}

\section{José Monteagudo Fernández José Luis Villa Arocena Pedro Miralles Martínez}

Universidad de Murcia

Resumen: Este artículo muestra las opiniones de los inspectores educativos respecto a las prácticas de evaluación de los profesores de Geografía e Historia de Educación Secundaria Obligatoria (ESO) en la Región de Murcia, concretamente lo relativo a instrumentos y fases de evaluación, las concepciones sobre la calificación y la evaluación por competencias básicas. Los datos han sido extraídos mediante cuestionarios. Los resultados indican que las prácticas de evaluación de los profesores de Geografía e Historia no han variado en el tiempo a pesar de la introducción de novedades legislativas. El examen basado en contenidos conceptuales sigue siendo el instrumento de evaluación más importante. Todo ello dificulta la innovación en el aula para un correcto desarrollo de las competencias básicas.

Palabras clave: evaluación del aprendizaje, competencias básicas, ciencias sociales, Educación Secundaria, inspectores educativos.

Abstract: This paper presents the opinions of the inspectors of schools regarding assessment practices teachers of Geography and History of Compulsory Secondary School (ESO) in the Region of Murcia, specifically with regard to tools and assessment phases, conceptions about mark and basic skills assessment. Data were extracted from questionnaires. The results indicate that assessment practices of teachers of Geography and History have not changed over time despite the introduction of new legislation. The exam, based in conceptual contents, remains the most important tool of assessment. All this difficults the innovation in the classroom for the proper development of basic skills.

Key words: Learning assessment, basic skills, social sciences, Compulsory Education, inspectors of schools.

(Fecha de recepción: julio, 2014, y de aceptación: abril, 2015)

DOI: 10.7203/DCES.29.3891 


\section{Introducción}

La introducción de las competencias básicas en el currículo comporta una serie de cambios didácticos en el proceso de enseñanza-aprendizaje de todas las disciplinas escolares, incluidas las ciencias sociales. Dichos cambios están relacionados con la enseñanza de determinados conocimientos, destrezas, habilidades, actitudes y valores para un completo desarrollo personal y social. Por tanto, las modificaciones en la enseñanza conllevan también cambios en las prácticas relacionadas con la evaluación, con sus métodos e instrumentos. Si tenemos ello en cuenta, la evaluación de los aprendizajes no puede sostenerse solamente en la adquisición de conocimientos disciplinares, sino que debe orientarse hacia la aplicación de dichos conocimientos en situaciones cotidianas (Tiana, 2011).

En este sentido, las ciencias sociales en sus diferentes disciplinas, como la historia, son útiles para la interacción del alumnado con el medio social y cultural y para la adquisición de esas destrezas y habilidades que exige la nueva normativa (Miralles, Molina y Santisteban, 2011; Navarro, 2008; Pagès, 2007; Prats, 2011).

Por tanto, para un correcto desarrollo de las competencias básicas es imprescindible una evaluación que se ajuste a la naturaleza de las mismas, lo que la convierte en un elemento esencial del proceso de enseñanza-aprendizaje. Ello supone abandonar la tradicional concepción de la evaluación como un hecho concreto final, y pasar a considerarla como un proceso que recorre toda la actividad educativa y que sirve, además de calificar, para orientar y motivar (Alfageme y Miralles, 2009); en suma, para mejorar.

Estos cambios legislativos y didácticos están en la senda de las tendencias renovadoras que desde hace varios años apuestan por implementar en las aulas aprendizajes activos basados en problemas ligados a la realidad para una mejor educación ciudadana a través de una evaluación formativa alejada del empleo exclusivo de los tradicionales exámenes como instrumento de evaluación hegemónico (Perrenoud, 2004, 2012).

Este artículo pretende averiguar la opinión de un sujeto educativo, los inspectores de Educación que, gracias a su experiencia y conocimiento sobre la evaluación que se practica en las aulas, se convierten en un referente a tomar en cuenta si se desea conocer cómo es la evaluación educativa y qué puede hacerse por perfeccionarla, ya que poseen una visión privilegiada: la del conjunto de centros educativos de la Región de Murcia sobre las prácticas evaluadoras. La Inspección es un actor clave en el mundo educativo, ya que posee grandes conocimientos de la realidad de las aulas debido a sus actividades de control, orientación e intervención. Por tanto, hemos indagado en la opinión de los inspectores educativos sobre la labor de evaluación que realizan los docentes de Geografía e Historia.

\section{Marco teórico}

En el sentido de lo apuntado, el aprendizaje de los alumnos ha de prepararlos 
para la vida resaltando valores de cooperación, solidaridad, compromiso, pensamiento propio, creación, innovación y generar una responsabilidad individual para que más tarde se transmita en una responsabilidad colectiva adecuada para la convivencia social. Para llevar todo ello a buen puerto es necesario que la evaluación busque el éxito de todos los alumnos, lo que pasa por su participación activa en el aula a través del diálogo con el docente y donde nadie se sienta el poseedor de la verdad absoluta, ya que la realidad social y política puede ser interpretada por diferentes visiones y criterios (Ordanza, s. f.).

La evaluación es un elemento fundamental en dicho proceso de enseñanzaaprendizaje. La introducción de las competencias básicas ha supuesto un nuevo replanteamiento de la misma hacia nuevas formas de evaluar que tengan en cuenta conceptos, procedimientos y actitudes, y al empleo de nuevos instrumentos de evaluación más cercanos a la realidad del alumnado que consigan un verdadera evaluación formativa, ayudando de esta forma a los discentes a aprender a desarrollarse personal y socialmente.

Escamilla (2011) define las competencias como un saber orientado a la acción, eficaz, fundamentado en conocimientos y valores, y que permite una adaptación ajustada a situaciones en diferentes contextos, por lo que el elemento fundamental para su desarrollo en el aula son los contenidos procedimentales, pero necesitando de actitudes que los promuevan y de conceptos como saber imprescindible para la acción.

Esto supone un cambio significativo en las prácticas tradicionales de evaluación. En primer lugar, la evaluación debería emplear varios instrumentos, además de los test o exámenes, como la observación diaria del aula, el análisis de las producciones de los alumnos (trabajos, cuadernos...), entrevistas, etc.; adaptando cada uno de ellos a los objetivos y contenidos que sean propósito de aprendizaje, para de esta forma evaluar todos los tipos de contenidos, ya que los alumnos necesitan adquirir de las ciencias sociales conocimientos científicos propios del área, resolver cuestiones prácticas diversas y desarrollar un pensamiento crítico, reflexivo y transformador (Gómez y Martínez, 1997).

En conexión con ello, se debe facilitar la participación activa de los alumnos en el aula a través de diálogos reflexivos con el docente, debates, mesas redondas, etc.; donde hablen libremente y muestren su pensamiento, lo que implica que pueden escoger los temas sobre los que trabajar y el empleo, por parte del docente, de técnicas cualitativas de evaluación que deben incluir, inevitablemente, la autoevaluación (Zemelman, Daniels y Hyde, 1998).

Pero, además del uso de la amplia panoplia de técnicas e instrumentos de evaluación mencionados, también es importante tener en cuenta las fases en las que se desarrolla la evaluación para responder correctamente a la valoración de la adquisición de las competencias básicas. Para ello es fundamental 
llevar a cabo las tres fases de la evaluación si queremos saber si el alumnado aprende o no. Un ejemplo es la propuesta realizada por Canals (2011) para la evaluación de la competencia social y ciudadana que, entendemos, podría hacerse extensiva al resto de competencias; un secuencia que respeta las tres fases de la evaluación: una primera, en la que se explicitarían los conocimientos previos de los alumnos con el fin de detectar percepciones y resultados de vivencias y experiencias personales, una segunda, donde desarrollar de situaciones ordinarias de aprendizaje en las que la evaluación alcanzaría una faceta formativa en la medida en que el profesor comprobase los aciertos y errores de los alumnos y les enseñase a gestionarlos; y una tercera fase que consistiría en la reproducción de situaciones y problemas lo más parecidos posibles a la realidad, con la intención de comprobar cómo los alumnos ponen en práctica los conocimientos adquiridos.

Esta propuesta de Canals sigue la senda abierta anteriormente por otros autores como Alonso (1991), Coll (1993) o Villa (2004), que, continuando las estrategias de Ausubel (1976), hablaban de aprendizajes significativos y métodos de enseñanza motivadores, comenzando por la comprobación de lo que el alumnado ya sabe para, posteriormente, trabajar tareas relacionadas con los intereses del alumnado y generalizar los aprendizajes alcanzados al contexto real.

En definitiva, de lo que estamos hablando es de implementar en la enseñanza y aprendizaje de las ciencias sociales una auténtica evaluación continua y formativa, aquélla que tiene en cuenta todos los datos obtenidos a lo largo del curso completo y que presenta un fin pedagógico de ayuda a los alumnos para aprender más y mejor, ya que no sólo se estima el logro de los aprendizajes previstos, sino también cómo los alumnos han conseguido aprenderlos, las posibles dificultades que han tenido para ello, los materiales que han empleado, el tiempo necesitado, etc. Toda esta información recabada tiene como fin esencial la reorientación del proceso educativo hacia cotas de mayor éxito (Triviño, 2008).

Sin embargo, las prácticas evaluativas en las clases de Ciencias Sociales no han cambiado en los últimos decenios. Y ello lo sabemos por nuestra propia experiencia docente, respaldada por autores como Trepat (2012), quien nos dice que a pesar de que en España hace ya cuarenta años que mutó la legislación a favor de una concepción más moderna de la evaluación, la realidad es que el ritmo de puesta en práctica de esas concepciones ha sido y es lento en los centros escolares.

En el caso de las Ciencias Sociales, Merchán (2005) afirma que el centro de la evaluación sigue siendo el examen, examen que no va más allá de la mera memorización de los hechos que aparecen en el libro de texto o en los apuntes del profesor. Sostiene que, a pesar de las últimas reformas educativas, el esquema de una clase de Historia actual apenas ha variado con respecto a la de 
hace un siglo: preguntas a los alumnos seguidas de una lección magistral llena de nombres, acontecimientos y fechas, muchas veces de la historia nacional.

La actual Ley Orgánica 8/2013, de 9 de diciembre, para la Mejora de la Calidad Educativa, LOMCE ha introducido los estándares de aprendizaje, definidos como especificaciones de los criterios de evaluación que permiten precisar los resultados de aprendizaje, y que concretan lo que el alumno debe saber, comprender y saber hacer en cada área. Esta ley especifica que dichos estándares deben ser observables, medibles, evaluables y contribuir al diseño de pruebas estandarizadas y comparables. En este sentido consideramos que prestan una escasa ayuda al hecho de que los aprendizajes no deben ser evaluados únicamente a través de exámenes y, menos aún, referirse en su mayor parte a contenidos memorísticos.

Supone ello continuar por la senda que ha llevado a que sean precisamente los exámenes el instrumento de evaluación más importante en la calificación del alumnado, tal y como mostraron Monteagudo y Villa (2011) cuando analizaron los criterios de calificación de las programaciones docentes de Ciencias Sociales. Los exámenes escritos suponían entre un $60 \%$ y un $80 \%$ de la nota, mientras que los trabajos individuales y grupales, así como de la corrección del cuaderno del alumno, rondaban entre un $10 \%$ o $30 \%$. Por su parte, la valoración de las actitudes en las programaciones docentes solía rondar el $10 \%$ o el $20 \%$.
Retomando los contenidos de los exámenes, las investigaciones de Villa y Alonso (1996) en la Comunidad de Madrid llegaron a la conclusión de que en Ciencias Sociales el recuerdo era la operación cognitiva más demandada, evaluándose sobre todo los hechos, seguidos de los conceptos y los procedimientos, aunque estos muy escasamente, y siendo las preguntas cortas y el ensayo los formatos de preguntas más empleados en los exámenes. Así pues, a pesar de los cambios normativos operados en nuestro país desde hace unos cuantos decenios, la realidad de las aula parece no haberse alterado.

Algo similar ocurre en la materias de Geografía en $3 .^{\circ}$ e Historia en $4 .^{\circ}$ de ESO en la Región de Murcia, donde los estudios de Monteagudo, Sánchez, Molina y Miralles (2011) para el primer caso, y Monteagudo y Villa (2011) para el segundo, determinaban que en los exámenes de estas materias se prioriza un aprendizaje memorístico de contenidos conceptuales que se evalúa mediante preguntas cortas y ensayo, en donde el alumnado recuerda conceptos y hechos fundamentalmente.

Finalmente, incluso en etapas no obligatorias las conclusiones son semejantes, tal y como arrojaba la tesis doctoral de Martínez Molina (2008) para el caso de los alumnos que cursaron $\mathrm{COU}$ o Bachillerato LOGSE en la Región de Murcia entre los años 1993 y 2003. $\mathrm{Su}$ estudio se centró en el recuerdo del alumnado acerca de sus clases de Historia en el último curso de instituto, las características de los exámenes y los 
criterios de calificación que seguía su profesorado. Quedó mostrado que los exámenes escritos de redacción era la técnica de evaluación más empleada por los profesores de Historia de Secundaria. Normalmente eran exámenes parciales en los que la superación de su contenido hacía que éste quedase eliminado en la prueba siguiente. En el caso de los exámenes en la materia de Historia de España, generalmente, eran dos los exámenes que se realizaban por evaluación con un promedio de cuatro preguntas que reclamaban, sobre todo, la memorización y repetición de los contenidos vistos en clase, contenidos de temática política en su mayor parte.

Comprobar hasta qué punto la realidad descrita se reproduce o se mantiene en las aulas de Ciencias Sociales, en opinión de los inspectores educativos, y tener constancia de las verdaderas consecuencias de la llegada de las competencias básicas con los últimos cambios legislativos es lo que ha motivado nuestra investigación, para así hallar posibles modificaciones en las prácticas de evaluación de acuerdo con dichas directrices legales.

Para ello hemos contado, como ya se ha advertido, con la opinión de un agente educativo que puede contribuir en buena medida a la mejora de la calidad de la educación debido al conocimiento que poseen sobre la situación de cada centro (Silva, 2013), a su función relacionada con la formación del profesorado (Martorell, 2011), la promoción de la autoevaluación de la práctica docente (Bolancé, Cuadrado, Ruiz y Sánchez,
2013), y más concretamente de aquellos aspectos referidos a la evaluación del alumnado (Polo, 2012). De esta forma podrían iniciarse y desarrollarse proyectos de mejora con respecto a la evaluación, aunque las prioridades políticas respecto a la misma no se corresponden posteriormente con la necesaria atención al desarrollo de dicha mejora (Hernández, 2005).

\section{Metodología de la investigación}

En este artículo tratamos de analizar algunos resultados obtenidos fruto de los proyectos de investigación "La evaluación de las competencias básicas en Educación Secundaria Obligatoria desde las ciencias sociales" (EDU201237909-C03-03), subvencionado por el Ministerio de Economía y Competitividad, y "Criterios, procedimientos e instrumentos de evaluación de los contenidos de Geografía e Historia en el segundo ciclo de Educación Secundaria Obligatoria” (08668/PHCS/08), financiado por la Fundación Séneca-Agencia de Ciencia y Tecnología de la Región de Murcia en el marco del II PCTRM 2007-2010.

La finalidad de esta investigación se centra en describir las prácticas de evaluación que se siguen en las materias de Ciencias Sociales en ESO en la Región de Murcia a través de los conocimientos de los inspectores educativos, un sujeto que, gracias a su experiencia y conocimiento, que incluye la evaluación que se practica en las aulas, se torna en un referente a tomar en cuenta si se desea conocer cómo es la evaluación educativa 
y qué puede hacerse por perfeccionarla, ya que poseen una visión privilegiada: la del conjunto de centros educativos de la Región de Murcia.

Para ello nos hemos centrado en dos objetivos de investigación:

1. Recabar la opinión de los inspectores educativos acerca de los procesos de evaluación que realizan los docentes de Geografía e Historia en las aulas.

2. Analizar dichas opiniones a fin de intentar vislumbrar buenas prácticas evaluadoras en el aula de Ciencias Sociales en Educación Secundaria Obligatoria.

La realización de este estudio se ha diseñado siguiendo el procedimiento de un estudio descriptivo mediante cuestionario, a través de una metodología cuantitativa, con el propósito de describir y analizar las prácticas de evaluación que llevan a acabo en las aulas de Educación Secundaria el profesorado de Geografía e Historia.

\section{Muestra}

La muestra de esta investigación ha estado compuesta por un total de veintitrés inspectores, más de la mitad del total, cuya labor abarcaba toda la Comunidad Autónoma de la Región de Murcia. El objetivo ha sido que el número de inspectores participantes fuese representativo de los cinco ámbitos geográficos en los que desarrolla su labor: Murcia Norte, Murcia Sur, Cartagena-Mar Menor, Guadalentín y Noroeste-Altiplano. En el momento del estudio, la Inspección de Educación de la Comunidad Autónoma de la Región de Murcia estaba integrada por una cincuentena de inspectores. De los veintitrés inspectores de esta muestra, veinte eran hombres y tres mujeres, todos con experiencia docente en los diferentes niveles educativos (Primaria, Secundaria, Bachillerato, FP, etc.), aunque sólo dos de ellos habían impartido previamente Geografía e Historia en Secundaria. Con una experiencia que iba desde uno a veinticuatro años como inspectores, cinco de ellos eran funcionarios de carrera, mientras que el resto estaba en comisión de servicios. Todos presentaban una formación mínima de licenciatura, y dieciocho de ellos habían colaborado previamente en grupos y proyectos de investigación/innovación educativa.

\section{Instrumentos para la obtención de información}

Nuestra intención ha sido la de recoger la mayor cantidad y variedad de datos posible. Sin embargo, dada la difícil accesibilidad por la constante movilidad de los inspectores debido al carácter de sus funciones y, por tanto, a la dificultad para reunirlos, así como la cantidad de variables a explorar y la necesidad de homogeneizar el tratamiento de los datos, optamos por la elaboración y administración de un cuestionario, idóneo para recoger información sobre las características habituales en un determinado grupo de personas (Colás, Buendía y Hernández, 2009). 
El cuestionario es un procedimiento clásico en las ciencias sociales para la obtención y registro de datos, y resulta apropiado para estudios descriptivos como el nuestro. A pesar de que registra la información de manera impersonal, permite, sin embargo, consultar a una población amplia de una manera rápida y económica, al tiempo que posibilita un reposado examen de las preguntas (García, 2003). Nuestra voluntad de recoger sistemáticamente información rigurosa de un actor educativo que posee amplios conocimientos de la realidad de lo que acontece en las aulas fue otra de las razones que nos impulsaron a optar por el cuestionario.

La revisión bibliográfica constituyó la base sobre la que se elaboró el cuestionario que debían responder los inspectores educativos. Tras la elaboración de varios borradores y diferentes revisiones de los mismos, se procedió a la validación por medio de un grupo de expertos, todos docentes universitarios. Quedó conformado un cuestionario que contaba con los datos identificativos y se basaba en cuatro bloques o categorías de contenido que tenían relación con los elementos objeto de evaluación por parte de los docentes de Geografía e Historia: el tipo de contenidos que se evalúa, los procedimientos e instrumentos de evaluación, las concepciones y actuaciones sobre la calificación de los profesores, y el trabajo y evaluación por competencias básicas.

El instrumento en cuestión estaba compuesto por 11 ítems de identificación y 49 ítems de valoración tipo
Likert en una escala de cinco opciones, además de otros tres ítems en los que se requería una respuesta múltiple de carácter cerrado a los encuestados. Todo ello facilitaba la posterior codificación y tratamiento informático de los datos. A través de la elaboración del cuestionario hemos pretendido asegurarnos, dentro de las ciencias sociales, de que medimos aquello que queremos medir y que nos acercamos de un modo más fiable a la investigación científica.

Para proceder al tratamiento de los datos obtenidos de los cuestionarios de los inspectores se ha utilizado la base de datos SPSS (Statistical Package for the Social Sciences), versión 17.0, considerada una herramienta muy potente para el tratamiento de datos y análisis estadístico, ya que se adapta perfectamente a las exigencias y rigurosidad de la investigación académica.

\section{Análisis e interpretación de los resultados}

Dada la extensión del cuestionario y las necesidades de síntesis para su difusión mediante un artículo, se expondrán a continuación los resultados más relevantes hallados en relación con los propósitos de nuestra indagación.

Comenzando con el primer bloque de preguntas, en las que se cuestionaba a los inspectores sobre qué tipo de contenidos evalúan los profesores en las materias de Ciencias Sociales, un 95\% de inspectores opina que en el aula se evalúan sobre todo contenidos de naturaleza conceptual (Gráfico I), opinión 
confirmada por los resultados de otras investigaciones sobre la misma etapa educativa (Monteagudo y Villa, 2011; Monteagudo, Sánchez, Molina y Miralles, 2011), e incluso en Educación Primaria (Miralles, Gómez y Monteagudo, 2012). También consideran, en otro
95\%, que los docentes evalúan lo que enseñan (Gráfico II), de lo que podemos deducir que los inspectores piensan que en el día a día del aula se trabajan sobre todo contenidos conceptuales por parte de los profesores.

\section{Gráfico I.}

Se evalúan sobre todo contenidos conceptuales.

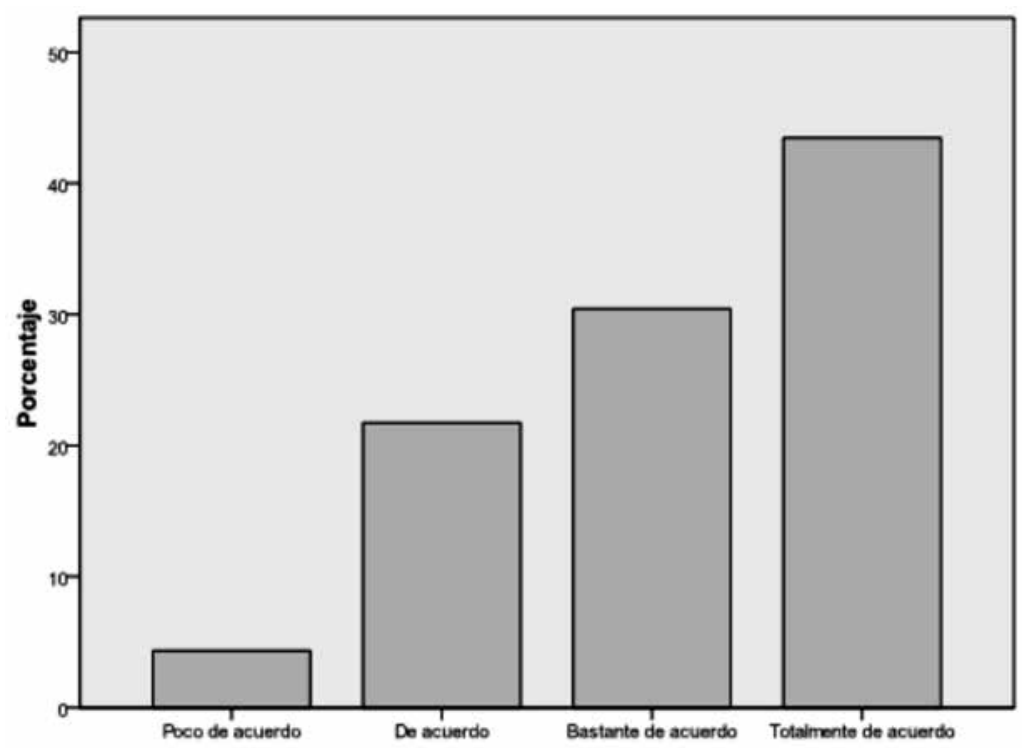

\section{Gráfico II.}

Se adaptan

los contenidos

enseñados a

los contenidos evaluados.

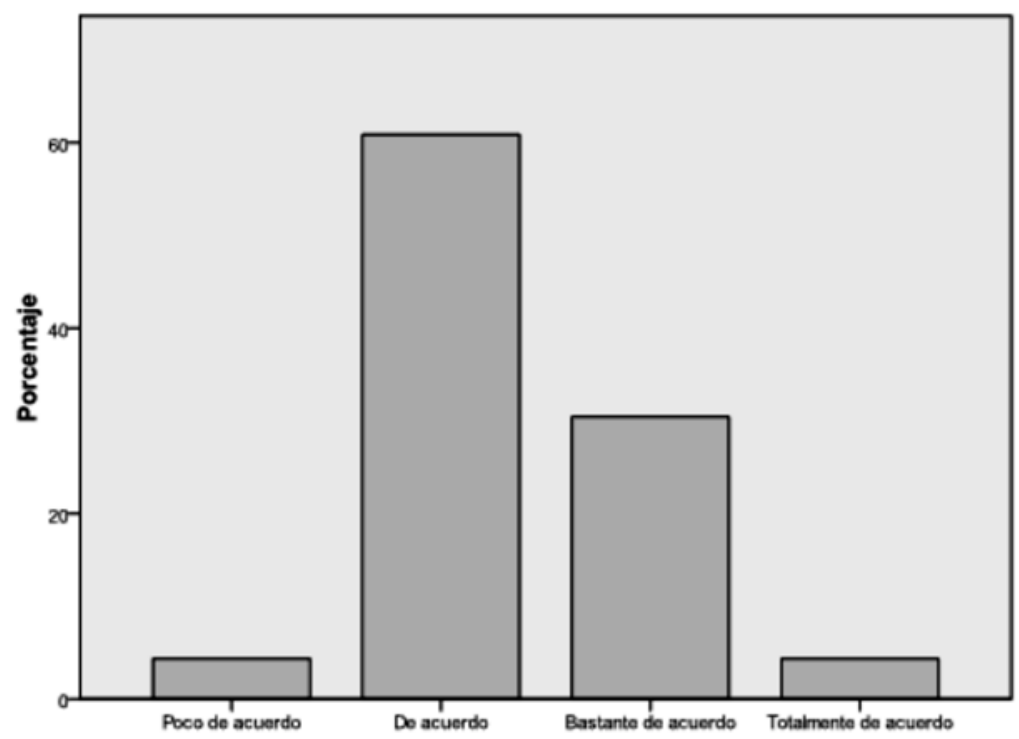


Por otro lado, como muestra la tabla I, un $78 \%$ de inspectores también considera que los docentes, en general, no adaptan la evaluación a las características de los alumnos que tienen delante ni a sus diferencias individuales, sino a las particularidades de la materia que imparten, por lo que todos los discentes, independientemente de su realidad, son medidos por el mismo rasero y éste varía en función de la asignatura.

\begin{tabular}{|c|c|c|c|c|c|}
\hline \multicolumn{6}{|c|}{$\begin{array}{c}\text { Tabla I } \\
\text { Los profesores adaptan la evaluación a las características de los } \\
\text { alumnos }\end{array}$} \\
\hline & & Frecuencia & Porcentaje & $\begin{array}{c}\text { Porcentaje } \\
\text { válido }\end{array}$ & $\begin{array}{l}\text { Porcentaje } \\
\text { acumulado }\end{array}$ \\
\hline \multirow[t]{6}{*}{ Válidos } & Totalmente en desacuerdo & 1 & 4,3 & 4,3 & 4,3 \\
\hline & Bastante en desacuerdo & 8 & 34,8 & 34,8 & 39,1 \\
\hline & Poco de acuerdo & 9 & 39,1 & 39,1 & 78,3 \\
\hline & De acuerdo & 3 & 13,0 & 13,0 & 91,3 \\
\hline & Bastante de acuerdo & 2 & 8,7 & 8,7 & 100,0 \\
\hline & Total & 23 & 100,0 & 100,0 & \\
\hline
\end{tabular}

Finalmente, más del $75 \%$ de los inspectores sostiene que los alumnos no escriben en los exámenes todo lo que saben y que aprenden más de lo que con este tipo de instrumento se alcanza a demostrar (Gráficos III y IV). Ello nos empuja a la conclusión de que los exámenes sólo ponen en juego parte de

\section{Gráfico III. \\ Lo que los estudiantes escriben en los exámenes refleja lo que saben.}

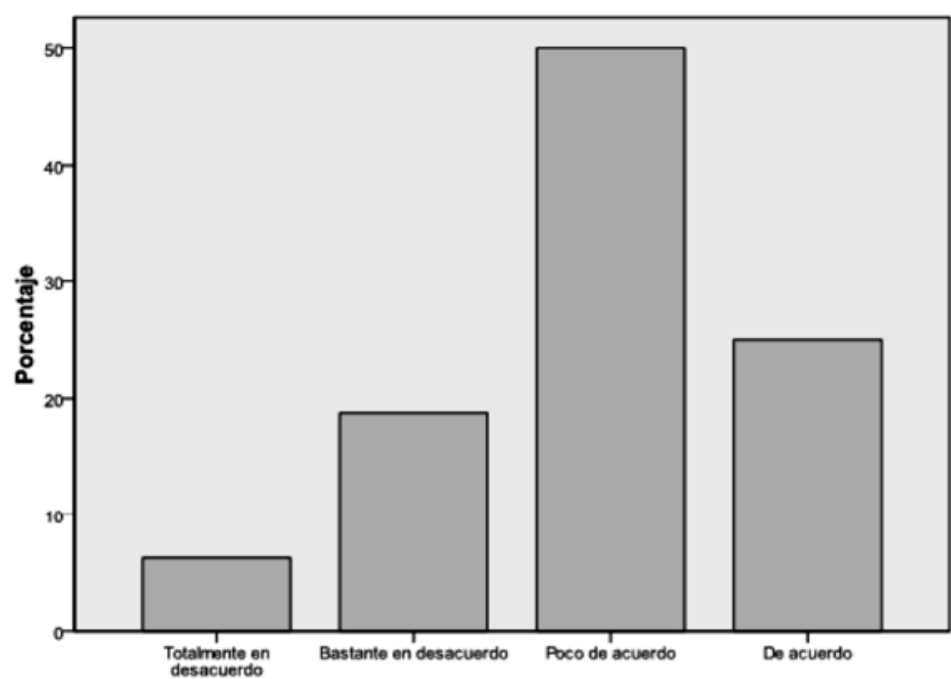


Gráfico IV.

Los estudiantes aprenden más de lo que reflejan los exámenes.

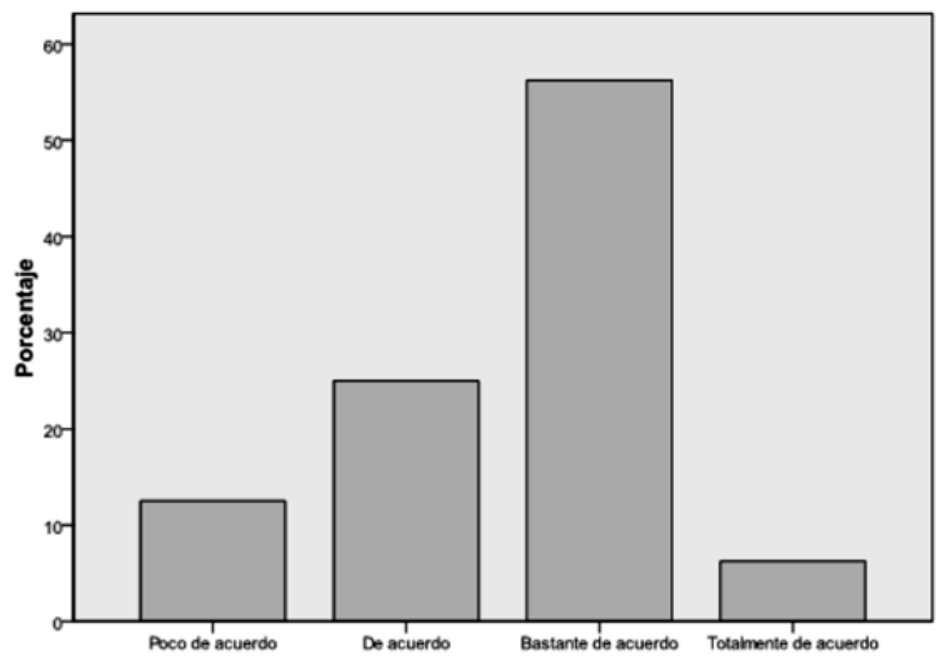

los conocimientos de los alumnos, por lo que el empleo de otros instrumentos de evaluación, como cuaderno o trabajos de clase, es necesario para un mejor y completo aprendizaje.

En el segundo bloque del cuestionario se preguntaba a los inspectores sobre los procedimientos e instrumentos de evaluación que utilizaban los profesores en las materias de Ciencias Sociales en ESO.

\section{Gráfico V.}

Los profesores evalúan aspectos cuantificables antes que competencias.

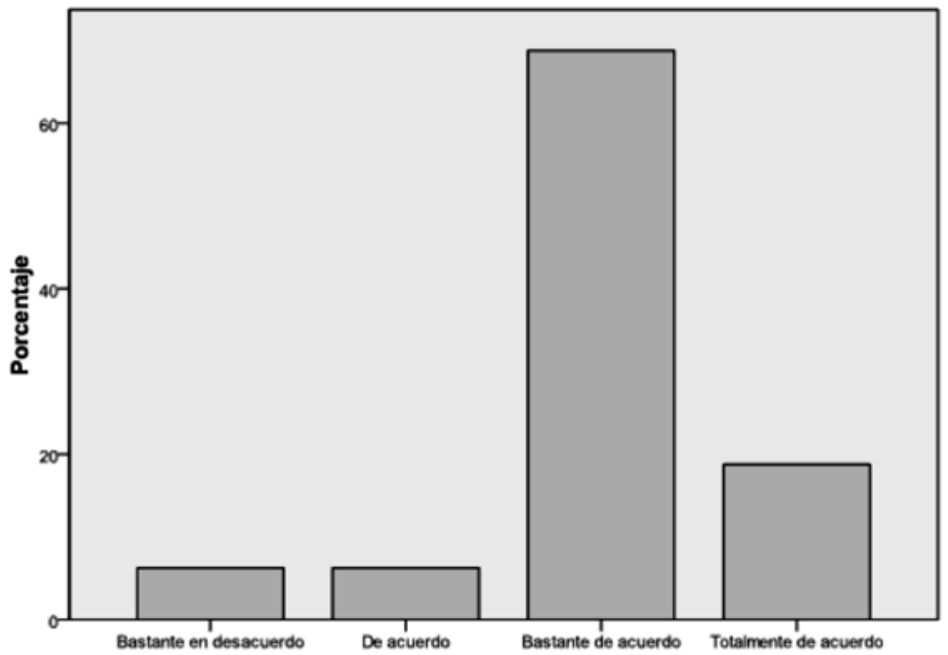


veces se traduce en exámenes, como luego comprobaremos.

En este punto, los gráficos VI y VII revelan que las prácticas tradicionales de evaluación suponen, en opinión de más del $90 \%$ de los inspectores, un freno a la hora de implementar cambios en la forma en la que los docentes abordan sus clases con los alumnos, debiendo de modificar el proceso de evaluación para poder cambiar su pedagogía e introducir elementos novedosos. Dicha afirmación coincide plenamente con la visión e importancia que expertos como Perrenoud (2008) atribuyen a la evaluación como piedra angular del sistema educativo. Sin variaciones en las formas de evaluar, no pueden llevarse a cabo cambios en la manera en que se desarrollan las clases diarias.
Gráfico VI.

Las prácticas

de evaluación

convencionales

impiden el cambio de

la práctica docente.

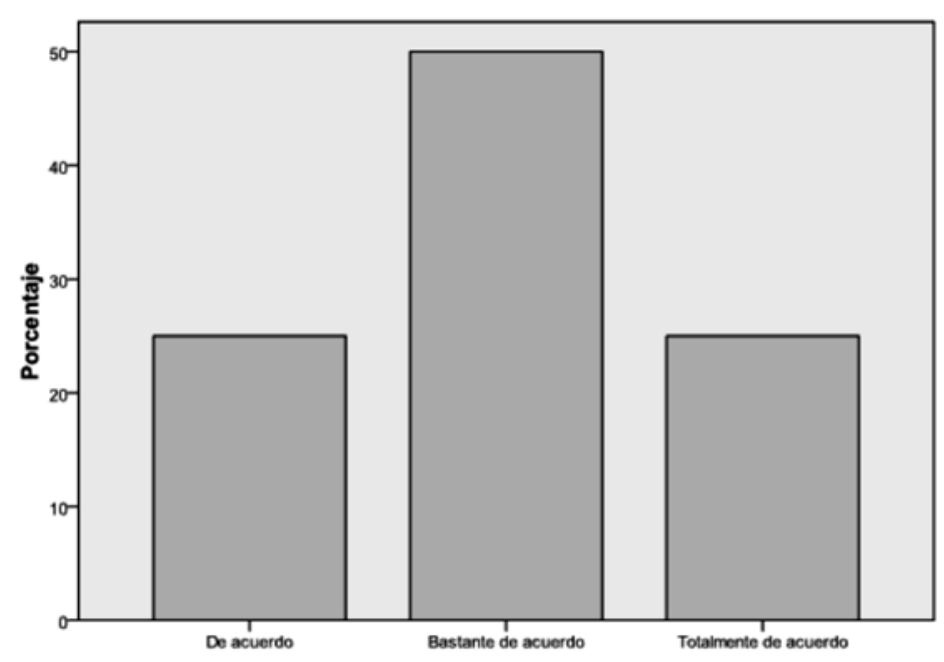

Gráfico VII.

Los profesores deben

cambiar la evaluación

para cambiar su

pedagogía.

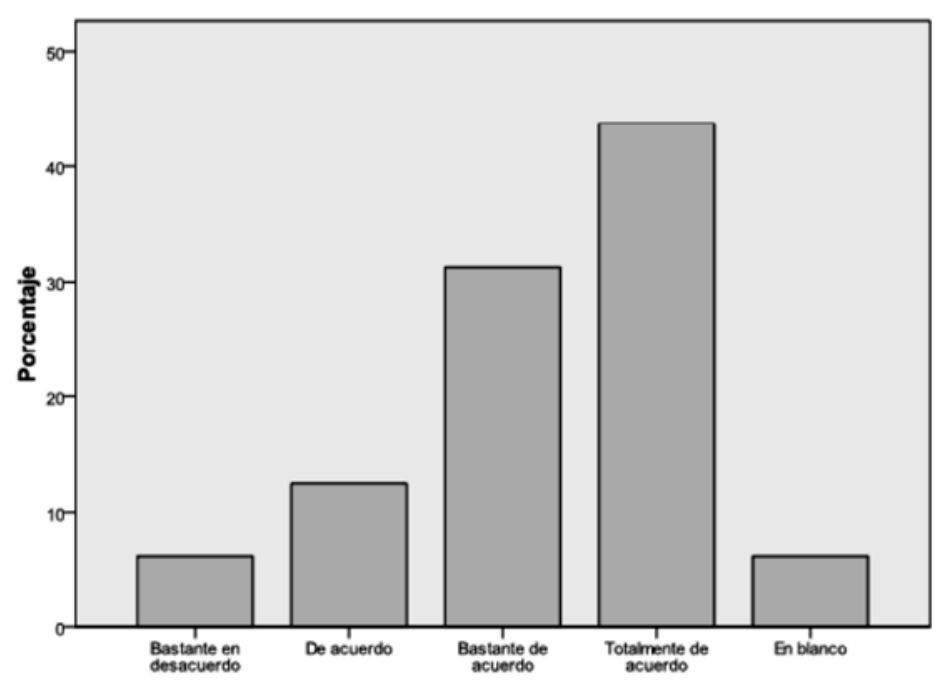


Una opinión significativa del 90\% de los inspectores en la Región de Murcia mantiene que gran parte del fracaso escolar se debe a las actuales formas de enseñar y evaluar (Gráfico VIII), que, como acabamos de ver a juicio de los inspectores, conservan perfiles tradicionales a pesar de la incorporación de conceptos como evaluación continua o competencias.

\section{Gráfico VIII.}

Los procedimientos de enseñanza o de evaluación pueden ser los responsables de buena parte del fracaso escolar.

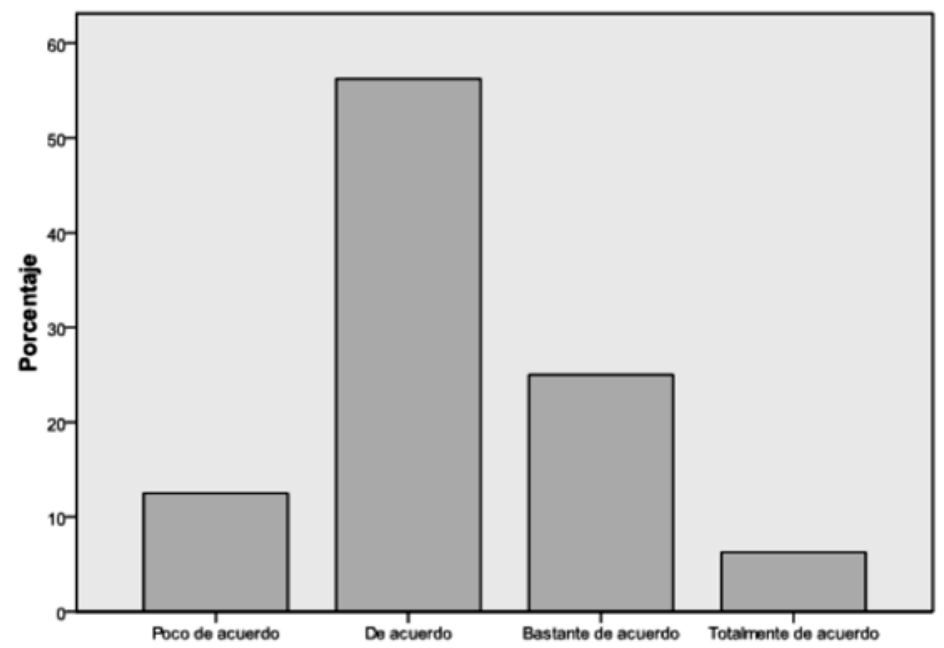

Un asunto central en la evaluación tiene que ver con las fases de la misma. Si se entiende la evaluación como un proceso, es algo que para casi el $70 \%$ de los inspectores no se da si observamos el gráfico IX, pues sostienen que los docentes evalúan a los alumnos al final del proceso de enseñanza-aprendizaje, dejando al margen la evaluación continua.

\section{Gráfico IX.}

Los profesores

habitualmente evalúan a los alumnos al final del proceso de enseñanzaaprendizaje.

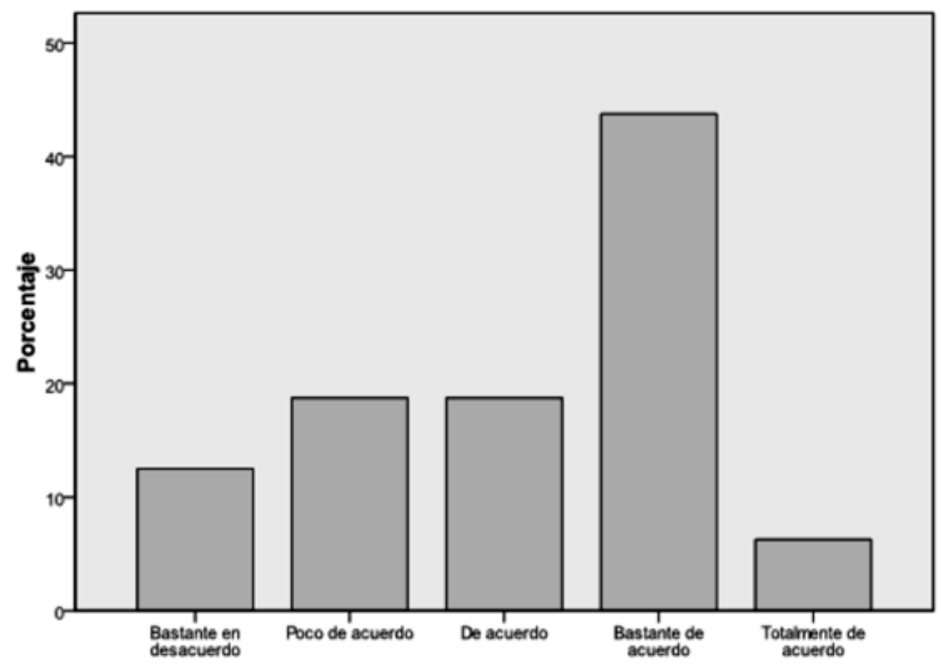


Continuando con las fases de la evaluación, y reforzando el predominio de la evaluación final sobre las demás fases de dicho proceso, casi un $90 \%$ de los inspectores mantiene que los docentes realizan la evaluación inicial por meras exigencias del sistema y no por la importancia pedagógica que posee la misma para averiguar el punto de partida de los alumnos (Gráfico X). Ello nos coloca ante la posibilidad de que, a pesar de las modificaciones en el terreno de la evaluación incorporadas en los últimos lustros, las concepciones docentes sobre la misma han variado muy poco con respecto a los pensamientos tradicionales.

\section{Gráfico X.}

\section{Para los profesores}

la evaluación inicial es más una exigencia administrativa que un interés pedagógico.

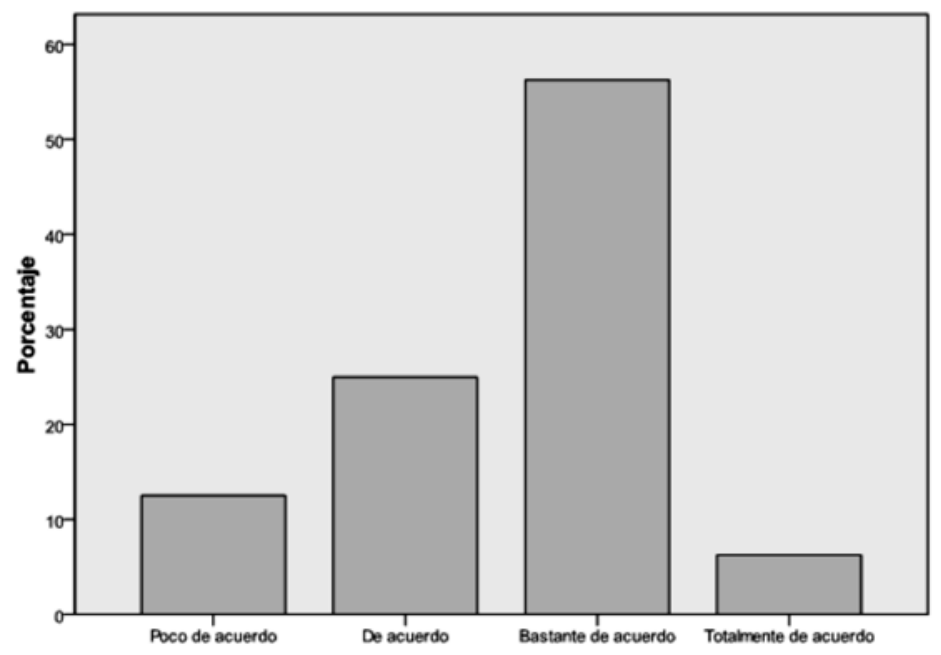

Otra de las cuestiones más relacionadas con nuestra investigación tiene que ver con los instrumentos de evaluación que emplean los docentes. En este ámbito, más del $60 \%$ de los inspectores sostiene que los profesores emplean una escasa variedad de instrumentos para evaluar a sus alumnos, como muestra el gráfico XI, estando en consonancia con el estudio de Monteagudo y Villa (2011), en el que la mayor parte de las programaciones de los centros participantes en la investigación recogían una media de cuatro instrumentos de evaluación (examen, cuaderno, trabajos, observa- ción). La revisión de la bibliografía y nuestra propia experiencia nos dice que de ese escueto abanico, y teniendo presente la opinión de los inspectores vista anteriormente en la que manifestaban que los profesores sólo evalúan al final del proceso de enseñanza-aprendizaje, la herramienta más empleada en estas circunstancias es el examen escrito.

Continuando con los instrumentos de evaluación, un 75\% de los inspectores opina que los docentes de las materias de Ciencias Sociales en ESO no utilizan procedimientos cualitativos para evaluar a sus alumnos (Gráfico XII), 
Gráfico XI.

Los profesores emplean gran variedad de instrumentos.

\section{Gráfico XII.}

\section{Los profesores utilizan} poco los procedimientos de evaluación cualitativos.
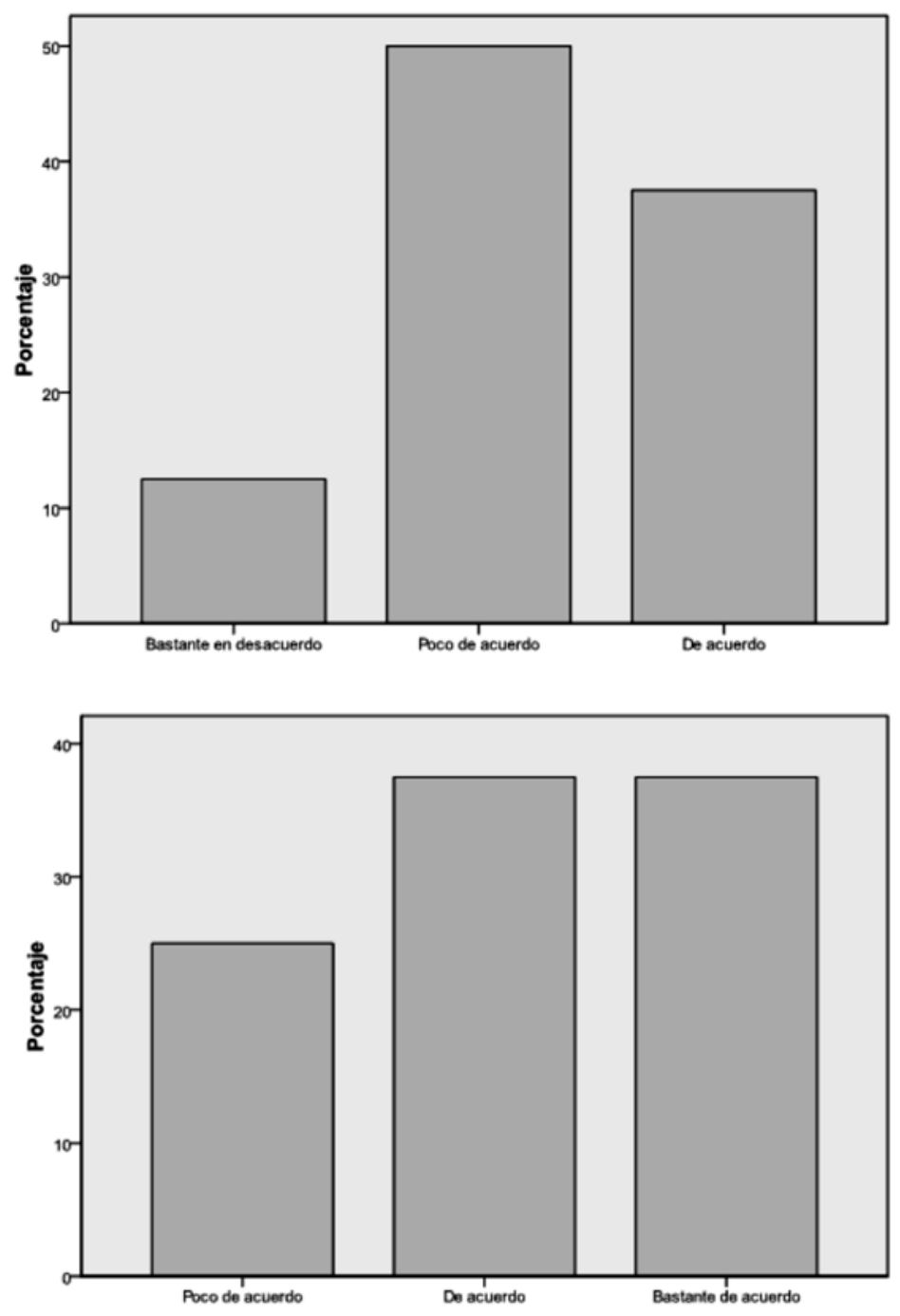

parecer que nos sitúa nuevamente ante la preponderancia de medios que pueden ser más cuantitativos, caso de los exámenes.

Sin abandonar los instrumentos, un $69 \%$ de los inspectores cree que el examen no es un instrumento imprescindible a la hora de evaluar a los alumnos ni el más objetivo (Tabla II), opinión que contrasta con la realidad de las aulas, como veremos más adelante cuando analicemos los instrumentos de evaluación que emplean los docentes a quienes orientan los inspectores, y con el criterio que estos mismos inspectores mantienen en la pregunta que viene a continuación (Gráfico XIII), en la que ni un solo inspector se posicionó en contra de que los exámenes son el instrumento más empleado a la hora de evaluar. 


\begin{tabular}{|ccccc|}
\hline \multicolumn{5}{|c|}{$\begin{array}{c}\text { Tabla II. El examen es el instrumento más objetivo: es necesario e } \\
\text { imprescindible para evaluar }\end{array}$} \\
\hline & Frecuencia & Porcentaje & $\begin{array}{c}\text { Porcentaje } \\
\text { válido }\end{array}$ & $\begin{array}{c}\text { Porcentaje } \\
\text { acumulado }\end{array}$ \\
\hline Válidos & & & 6,3 & 6,3 \\
Totalmente en desacuerdo & 1 & 4,3 & 18,8 & 25,0 \\
Bastante en desacuerdo & 3 & 13,0 & 43,8 & 68,8 \\
Poco de acuerdo & 7 & 30,4 & 12,5 & 81,3 \\
De acuerdo & 2 & 8,7 & 12,5 & 93,8 \\
Bastante de acuerdo & 2 & 8,7 & 6,3 & 100,0 \\
Totalmente de acuerdo & 1 & 4,3 & 100,0 & \\
Total & 16 & 69,6 & & \\
Perdidos Sistema & 7 & 30,4 & & \\
Total & 23 & 100,0 & & \\
\end{tabular}

\section{Gráfico XIII.}

La evaluación del

alumno por medio de exámenes es la práctica más extendida y utilizada.

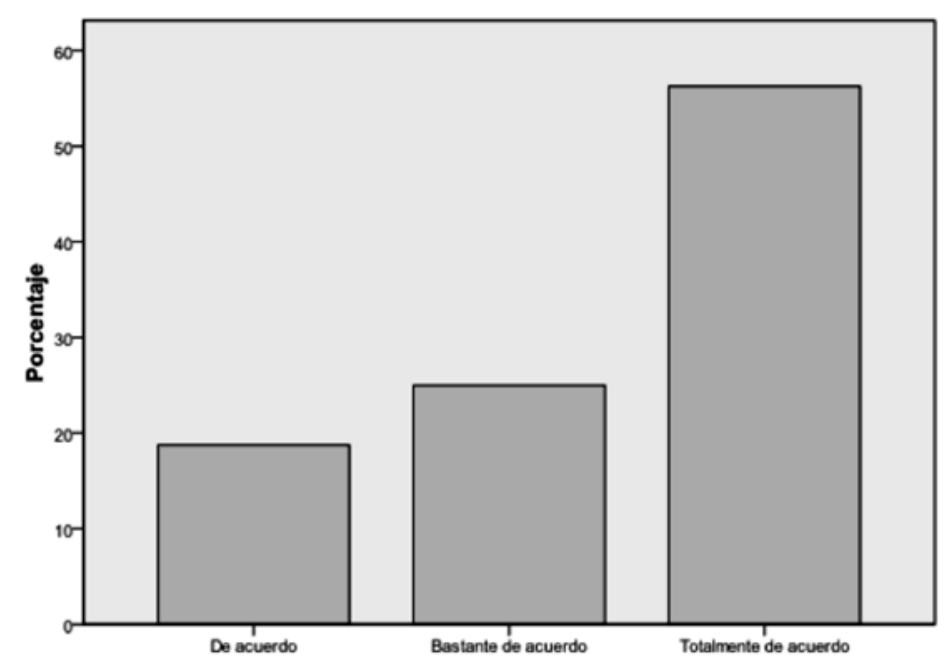

La práctica de los exámenes tiene una consecuencia negativa, y es que favorece a un determinado grupo de estudiantes sobre otros, generalmente a los de estable situación económico-social, por lo que no proporcionan igualdad de oportunidades y van en contra de uno de los pilares de la educación. Al menos así lo expresa casi el 95\% de los inspectores encuestados (Gráfico XIV). Si, como hemos visto en la cuestión anterior, el examen es el instrumento de evaluación más empleado, cabe preguntarse si la escuela sigue actuando como filtro que elimina a los más desfavorecidos y reproduce la estructura social existente. 
Gráfico XIV.

Los exámenes

favorecen a

determinados

grupos sociales $\mathbf{y}$

no proporcionan

una igualdad de

oportunidades.

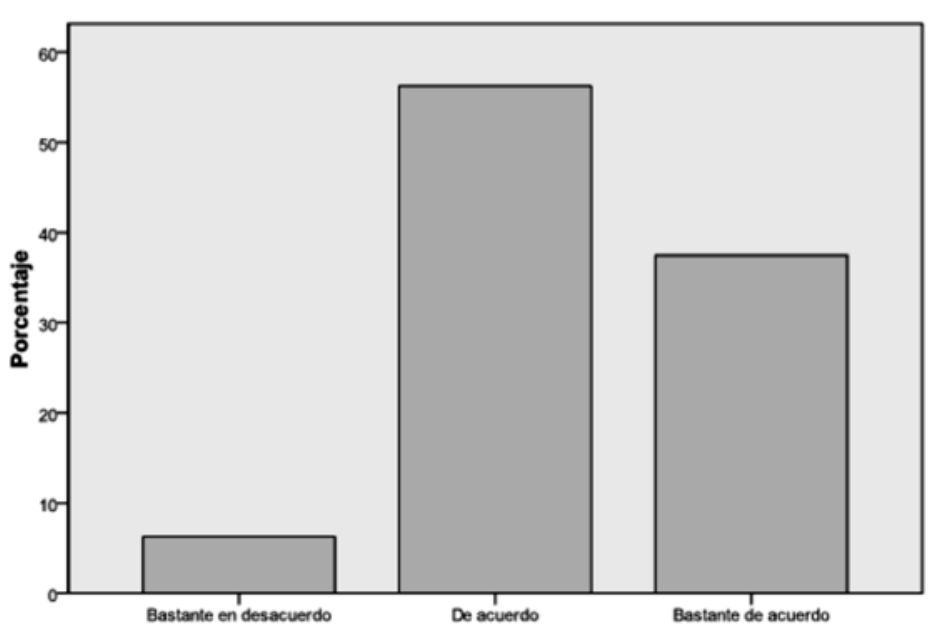

La contestación de un $75 \%$ de inspectores afirmando que el día a día en el ámbito educativo se reduce a una permanente preparación de exámenes (Tabla III), no hace sino apuntalar la teoría de Álvarez Méndez (2008) de que en las aulas se examina mucho y se evalúa poco, absorbiendo los exámenes gran parte de la actividad del docente y de los alumnos (Merchán, 2005) y sien- do el centro en torno al cual gravita el sistema educativo, con las posibles consecuencias que ya se han anunciado.

El hecho de que casi el $95 \%$ de los inspectores asevere que los docentes no usan la autoevaluación como mecanismo de evaluación, tal y como puede comprobarse en el gráfico XV, nos pone de nuevo sobre la afirmación de que en las aulas, en lo que respecta a la evalua-

\section{Tabla III. La vida escolar se reduce a una permanente preparación de exámenes}

\begin{tabular}{|c|c|c|c|c|c|}
\hline & & Frecuencia & Porcentaje & $\begin{array}{c}\text { Porcentaje } \\
\text { válido }\end{array}$ & $\begin{array}{l}\text { Porcentaje } \\
\text { acumulado }\end{array}$ \\
\hline \multirow[t]{6}{*}{ Válidos } & Bastante en desacuerdo & 1 & 4,3 & 6,3 & 6,3 \\
\hline & Poco de acuerdo & 3 & 13,0 & 18,8 & 25,0 \\
\hline & De acuerdo & 7 & 30,4 & 43,8 & 68,8 \\
\hline & Bastante de acuerdo & 4 & 17,4 & 25,0 & 93,8 \\
\hline & Totalmente de acuerdo & 1 & 4,3 & 6,3 & 100,0 \\
\hline & Total & 16 & 69,6 & 100,0 & \\
\hline \multicolumn{2}{|c|}{ Perdidos Sistema } & 7 & 30,4 & & \\
\hline & Total & 23 & 100,0 & & \\
\hline
\end{tabular}


ción, no se introducen prácticas novedosas que den mayor protagonismo a los alumnos y a otros elementos que los meramente conceptuales medibles a través de los exámenes.

El hecho de que no exista evaluación continua queda refrendado por la opinión de un 95\% de inspectores, representada en el gráfico XVI, donde éstos están de acuerdo en que sólo se realizan exámenes. En este punto parece confirmar- se la opinión de Álvarez Méndez (2008) de que en la escuela se ha confundido evaluación continua con examen.

Un último ítem en el segundo bloque del cuestionario trataba acerca de los instrumentos de evaluación que emplean los docentes. Al poder elegir entre varias opciones a la vez, el resultado aparece por grupos de respuestas, tal y como puede verse en la tabla IV. Examinándolas se comprueba cómo el

\section{Gráfico XV.}

Los profesores emplean la autoevaluación como complemento de otros procedimientos de evaluación.

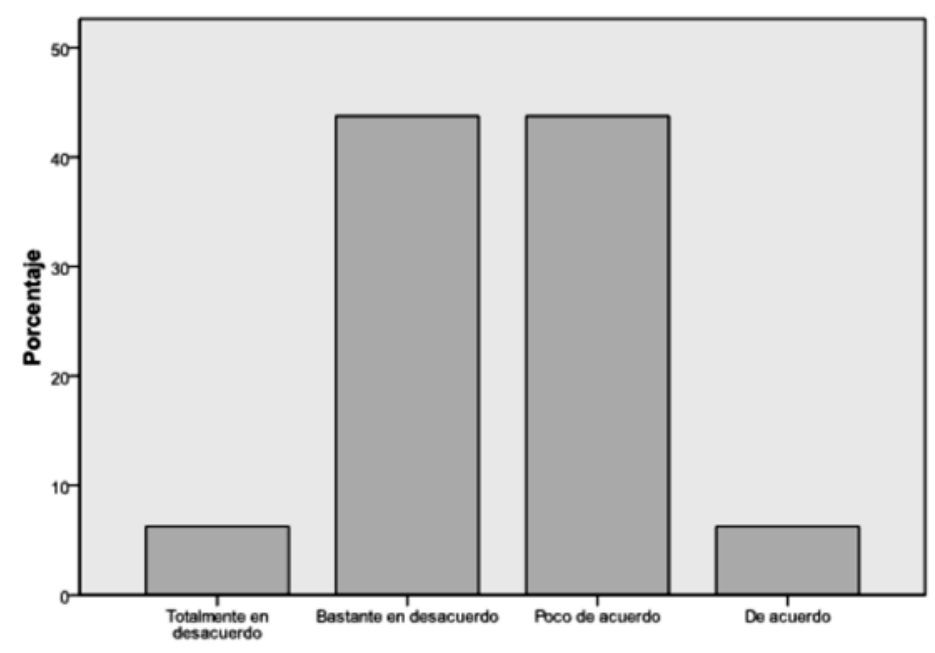

\section{Gráfico XVI.}

No se practica la evaluación continua, sólo exámenes continuos.

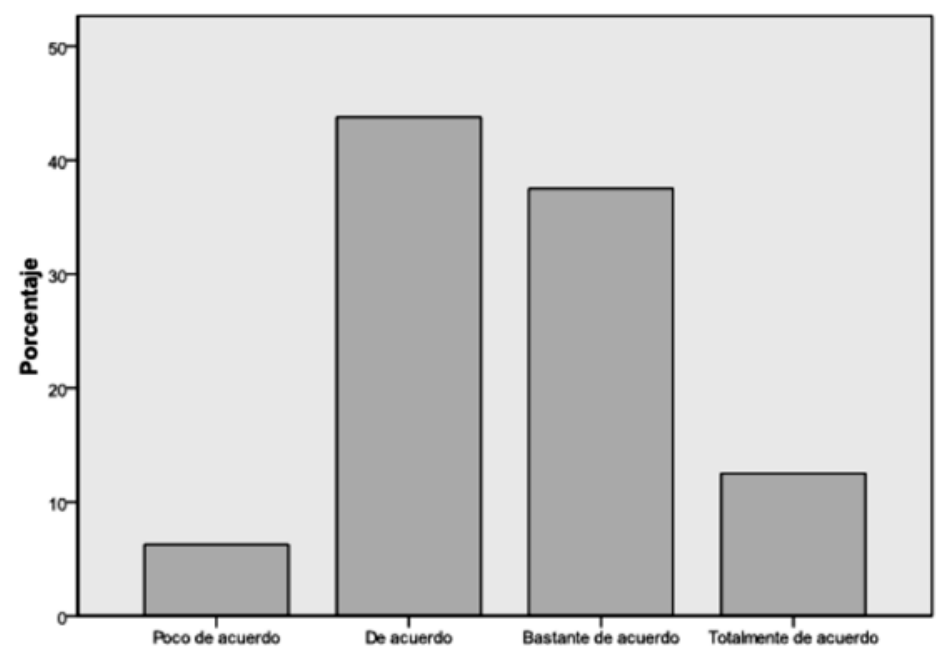




\section{Tabla IV. Instrumentos de evaluación que utilizan los profesores de Geografía e Historia}

Frecuencia Porcentaje Porcentaje acumulado

Válidos Cuadernos de clase, exámenes escritos de desarrollo y exámenes o pruebas objetivas

Exámenes orales, cuadernos de clase, exámenes escritos de desarrollo y trabajos en clase

Cuadernos de clase, exámenes escritos de desarrollo, exámenes o pruebas objetivas y trabajos en clase

Cuadernos de clase, exámenes escritos de desarrollo y trabajos de clase

Cuadernos de clase, exámenes escritos de desarrollo, exámenes o pruebas objetivas, trabajos de clase y preguntas orales en clase no preparadas.

Trabajos en clase, exámenes escritos de desarrollo y exámenes o pruebas objetivas

Cuadernos de clase, exámenes escritos de desarrollo, exámenes o pruebas objetivas y trabajos en clase y carpeta de trabajos o portafolio Trabajos en clase, exámenes escritos de desarrollo y carpeta de trabajos o portafolios

Cuadernos de clase, exámenes escritos de desarrollo y exámenes o pruebas objetivas y trabajos fuera de clase

Cuadernos de clase y exámenes escritos de desarrollo

Cuadernos de clase, exámenes escritos de desarrollo, exámenes o pruebas objetivas, trabajos en clase, carpeta de trabajos 0 portafolio y exámenes orales

Cuadernos de clase, exámenes escritos de desarrollo, exámenes o pruebas objetivas, trabajos en clase y exámenes orales

Trabajos en clase y exámenes escritos de desarrollo 
conjunto de Exámenes orales, cuadernos de clase, exámenes escritos de desarrollo y trabajos en clase es el mayoritario, ligeramente por encima de los grupos de Cuadernos de clase, exámenes escritos de desarrollo y exámenes o pruebas objetivas, de Cuadernos de clase, exámenes escritos de desarrollo y trabajos de clase, y de Trabajos en clase, exámenes escritos de desarrollo y exámenes o pruebas objetivas. El resto de grupos, con el mismo porcentaje, a excepción de Cuadernos de clase, exámenes escritos de desarrollo, exámenes o pruebas objetivas y trabajos en clase, con más de un $8 \%$, presenta una importancia menor. Siguiendo las pautas de los tres primeros grupos, e individualizando los instrumentos aparecidos, en las respuestas de los inspectores puede observarse que son los exámenes escritos de desarrollo, seguidos de los cuadernos de los alumnos, los trabajos en clase y los exámenes de pruebas objetivas, los principales instrumentos que utilizan los docentes para evaluar a sus alumnos de ESO en la Región de Murcia.

Por encima de todo se hayan los exámenes, en cualquiera de sus maneras, sobre los demás. En el otro extremo aparecen las preguntas y los exámenes orales, el portafolio y los trabajos fuera de clase. Ello confirma que las nuevas formas de evaluar no han hecho acto de presencia prácticamente en el ámbito de la Educación Secundaria en la Región de Murcia.

En un tercer bloque de preguntas, a los inspectores se les interrogó por el pensamiento y actuación de los profesores de Geografía e Historia sobre la calificación de los alumnos. Para cerca del $80 \%$ de los inspectores encuestados, los docentes identifican evaluación con calificación (Gráfico XVII), cuestión que ya adelantó López Facal (1997), no llegando así a distinguir la diferencia existente entre ambas que realizan Santos Guerra (2003) y Álvarez Mén$\operatorname{dez}$ (2008), para quienes la evaluación

\section{Gráfico XVII.}

Para los docentes, la evaluación se reduce a calificación.

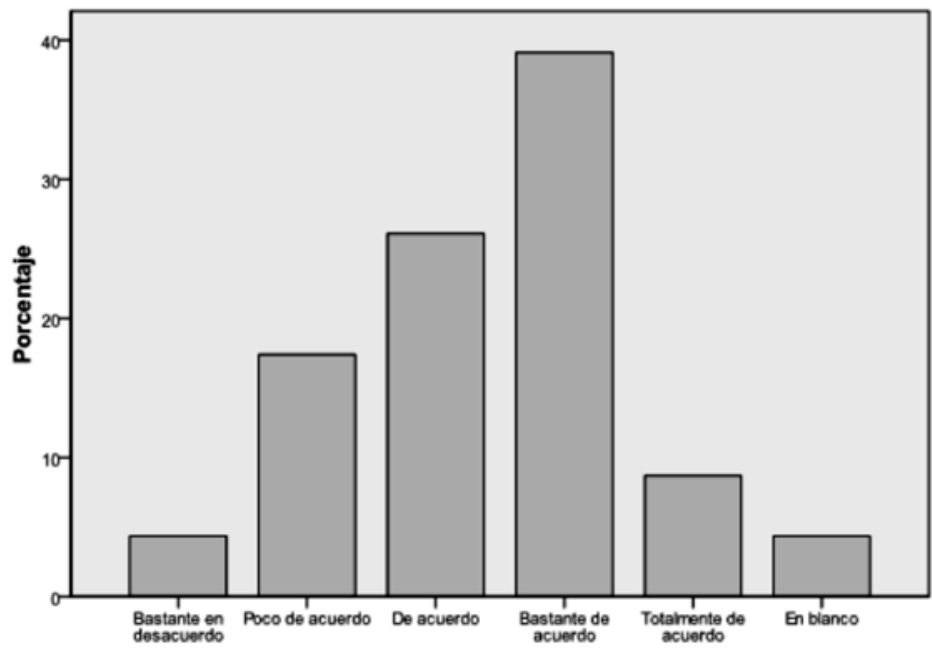


está por encima de ellas al considerarse actividad de aprendizaje.

El hecho de que sean los exámenes la herramienta que más peso tiene a la hora de obtener la calificación de los alumnos, como mostraban Monteagudo y Villa en su estudio (2011) y el centro de la actividad en las aulas, queda refrendado por el parecer de los inspectores. Todos ellos, en mayor o menor medida, aseguran que los alumnos de los docentes a quienes orientan dan más importancia a los exámenes que a otro tipo de actividades por la mayor importancia que se le otorga a éstos cara a la calificación final (Gráfico XVIII).

Finalmente, un cuarto bloque de preguntas tenía que ver con las competencias básicas y su evaluación. En la primera cuestión, un 78\% de los inspectores encuestados consideran que en los centros educativos en los que se imparten enseñanzas de ciencias sociales en ESO no se está evaluando por competencias (Tabla V), lo que nos hace pensar que el verdadero alcance de éstas en los procesos de evaluación es muy limitado.

\section{Gráfico XVIII.}

Los alumnos dan más importancia al examen por la calificación final que reciben.

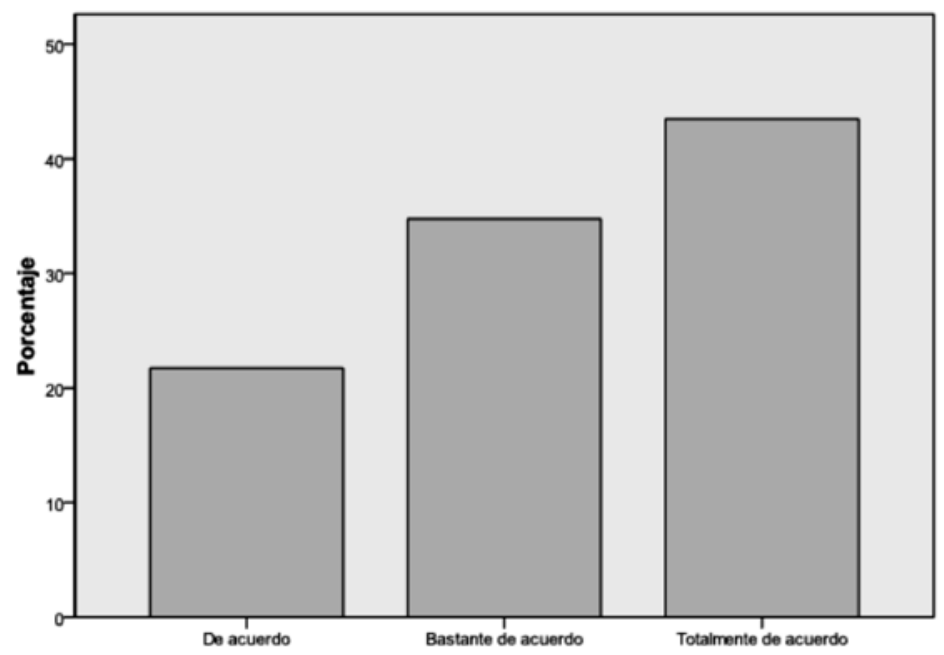

\begin{tabular}{|llcccc|}
\hline \multicolumn{6}{|c|}{ Tabla V. En los centros de ESO se trabaja la evaluación por } \\
competencias básicas \\
\hline
\end{tabular}




\begin{tabular}{|c|c|c|c|c|c|}
\hline & & Frecuencia & Porcentaje & $\begin{array}{c}\text { Porcentaje } \\
\text { válido }\end{array}$ & $\begin{array}{l}\text { Porcentaje } \\
\text { acumulado }\end{array}$ \\
\hline \multirow[t]{3}{*}{ Válidos } & No & 21 & 91,3 & 91,3 & 91,3 \\
\hline & Sí & 2 & 8,7 & 8,7 & 100,0 \\
\hline & Total & 23 & 100,0 & 100,0 & \\
\hline
\end{tabular}

Sin embargo, en los escasos casos positivos (21\%) en los que los inspectores aseguran que los departamentos están tratando el tema de la evaluación de las competencias básicas, más del 90\% de ellos opina que dicho trabajo no se aplica a la realidad de las aulas (Tabla VI), por lo que se trata de meras actuaciones teóricas que pueden realizarse para, como se dice coloquialmente, cubrir el expediente con las obligaciones y requerimientos administrativos, no dándose verdaderamente en la práctica. Ello nos vuelve a situar en el debate de si las competencias básicas tienen auténtico recorrido en las aulas o son meras construcciones teóricas que, como en otras ocasiones, no han aportado cambios substanciales a la vida educativa.

\section{Conclusiones e implicaciones}

Recapitulando las opiniones de los inspectores educativos de la Región de Murcia queda claro que para el $100 \%$ de los inspectores el peso de las evaluaciones reside en los exámenes como herramienta principal, exámenes con- feccionados a base des contenidos conceptuales. La importancia de dichos exámenes hace que la mayor parte de la vida escolar gire en torno ellos, y más cuando su peso en la calificación final es decisivo.

Las respuestas de los inspectores ponen de manifiesto que las concepciones y formas de evaluar que presentan los docentes de Geografía e Historia no han variado en el tiempo a pesar de la introducción de novedades legislativas. Este hecho pesa como una losa para que los docentes implementen en el aula nuevas formas de enseñar y de evaluar, formas que, manteniendo sus estándares tradicionales, pudieran ser, en parte, responsables del fracaso escolar, ya que la evaluación no se adapta a las características e individualidades del alumnado, midiéndolos a todos por el mismo rasero.

Estas viejas concepciones de la evaluación que siguen presentes en las aulas de hoy se reflejan en que la evaluación, tomada como algo puntual, ya que no se lleva a cabo la evaluación continua sino solamente final en la mayoría de los casos, es sinónimo de calificación. 
Así lo afirma alrededor de un $80 \%$ de los inspectores. Como ya hemos apuntado, se trata de una evaluación centrada en los exámenes donde, en opinión de un $75 \%$ de los inspectores, los alumnos no escriben todo lo que saben o han aprendido, al tiempo que los docentes no evalúan todo lo que enseñan, lo que empuja a la búsqueda de nuevas formas e instrumentos para evaluar, tales como la autoevaluación, los portafolios, los trabajos de investigación, etc.

Retomando el asunto de las novedades legislativas, de las respuestas de los inspectores deducimos que no se está trabajando ni evaluando por competencias básicas en la realidad de las aulas, a pesar de que lo estipulado en la normativa se recoja en las programaciones docentes. Sin embargo, ello sólo supone un cumplimiento del expediente, porque las escasas demandas de ayuda a los propios inspectores en un asunto como éste no hacen sino evidenciar el débil tratamiento de las competencias básicas cuando, debido a su problemática y a las discusiones que genera (Monteagudo y Villa, 2011), debería de ser objeto de mayor asesoramiento.

La realidad descrita supone que en las asignaturas de Ciencias Sociales en la etapa de ESO en la Región de Murcia se sigue evaluando con prácticas tradicionales que apenas han evolucionado con el paso del tiempo y de las sucesivas reformas educativas con sus correspondientes novedades. La aparición de los estándares de aprendizaje con la LOMCE no asegura, como mostraron las conclusiones de investigacio- nes como las citadas de Villa y Alonso (1996), y Monteagudo y Villa (2011) con currículos anteriores, que no vuelva a ocurrir lo mismo con la nueva legislación, pues los cambios necesarios para desarrollar una evaluación actualizada no siempre deben venir acompañados de cambios normativos, sino de cambios en los modos de hacer del profesorado mediante las diferentes vías que a continuación proponemos.

En primer lugar, como ya sostenía Santos Guerra (2003), planteamos la urgente necesidad de mejorar la formación docente en el terreno pedagógico y didáctico en general, y en la evaluación en particular, tanto de los futuros docentes, a través de una profunda reforma de los planes universitarios, como de los actuales profesores mediante cursos de formación y actualización. Dicha formación ha de basarse en una nueva concepción de la evaluación como proceso, como herramienta formativa y de aprendizaje (Álvarez, 2008).

En segundo lugar, la mencionada mejora en la formación docente en el área de ciencias sociales pasaría por una renovación metodológica que favoreciera métodos y estrategias activas que fomentasen la actuación autónoma del alumnado, empezando por el uso de técnicas de adquisición y manejo de información, colocándolo frente a situaciones prácticas que requiriesen de conocimientos, habilidades y actitudes para poder responder positivamente a dichas situaciones, no sin antes haber pasado por un proceso de meditación y razonamiento para llegar a las posibles 
soluciones, lo que ayuda al desarrollo del pensamiento crítico de los discentes (Canals, 2013). Nos referimos al trabajo mediante proyectos, ABP o estudios de caso, los cuales resultan, al mismo tiempo, útiles como ejercicio de evaluación para valorar la comprensión global de diferentes fenómenos históricos, geográficos y sociales, avanzando así hacia una comprensión contextualizada, que supone entender situaciones sociales en tiempos y lugares diferentes, relacionar pasado, presente y futuro, y generar nuevas hipótesis de investigación y conocimiento (Barca, 2004).

En tercer lugar, la aludida mejora en la formación docente también debería incorporar el empleo de una mayor variedad de instrumentos de evaluación además de los tradicionales exámenes, que han de dejar de ser el principal recurso para calificar a los alumnos. Nos referimos al uso de técnicas e instrumentos de carácter cualitativo que permitan una mayor autonomía y formación de los estudiantes, tales como los portafolios, las rúbricas, la autoevaluación, la coevaluación, etc. Todo ello constituye una pluralidad de técnicas de evaluación alternativa o cualitativa que posibilita una ampliación de la información del aprendizaje de los alumnos y realizar una evaluación formativa, al tiempo que permiten comprobar la adquisición de conocimientos y las competencias, ayudando a la autorregulación de los aprendizajes y proporcionan mayor interacción entre docentes y discentes (Alfageme y Miralles, 2009).
Tanto la metodología como la evaluación deberían de fomentar el trabajo con fuentes de información (Molina, Ortuño y Miralles, 2011), históricas y geográficas, que posibilitasen desplazar el foco desde los conocimientos memorísticos y repetitivos a otros más comprensivos, permitiendo, no sólo aprender ciencias sociales, sino aprehenderlas, pues facilitan herramientas intelectuales esenciales para explicar e intervenir en la realidad del alumnado.

En cuarto lugar, sin renunciar al examen como instrumento de evaluación, creemos necesario una modificación de los mismos como herramienta evaluativa. Con el fin de abandonar su perfil memorístico, éstos se han de elaborar en torno a ejercicios más complejos que pongan en funcionamiento aspectos procedimentales de aplicación, más relacionados con las competencias básicas, como comentarios de texto, imágenes, mapas, etc.; así como ejercicios de valoración o evaluación que también demanden la puesta en juego de elementos actitudinales. Se trataría, en definitiva, de incorporar ejercicios que promuevan la reflexión y la argumentación de respuestas fruto de la asimilación y comprensión del conocimiento (Álvarez, 2008), permitiendo así al alumnado la integración de ese conocimiento en su funcionamiento habitual sobre los problemas sociales (Carretero y Asensio, 1988).

Finalmente, no podemos dejar recordar las diferentes propuestas que desde hace ya varios años existen para el trabajo de las capacidades y competencias 
(Alonso, 1991; Coll, 1993; Villa, 2007; o Canals, 2011) que han de adquirir los discentes en base a un aprendizaje significativo y motivador. Estudiar, divulgar y aplicar dichas proposiciones sería una solución a los problemas que parece que genera la introducción de las competencias básicas.

\section{Referencias bibliográficas}

ALFAGEME, M. ${ }^{a}$ B. y MIRALLES, P. (2009). Instrumentos de evaluación para centrar nuestra enseñanza en el aprendizaje de los estudiantes. Íber. Didáctica de las Ciencias Sociales, Geografía e Historia, 60, 8-20.

ALONSO, J. (1991). Motivación y aprendizaje en el aula. Cómo enseñar a pensar. Madrid: Santillana.

ÁLVAREZ, J. M. (2008). Evaluar para conocer, examinar para excluir. Madrid: Morata.

AUSUBEL, D. P. (1976). Psicología educativa: un punto de vista cognoscitivo. México: Editorial Trillas.

BARCA, I. (2004). Aula oficina: do projecto à avaliação. En I. BARCA (Org.), Para uma Educação Histórica de Qualidade (131-144). Braga: CIEd.

BOLANCÉ, J., CUADRADO, F., RUIZ, J. R. y SÁNCHEZ, F. (2013). La autoevaluación de la práctica docente como herramienta para la mejora del proceso de enseñanza y aprendizaje del alumnado. Avances en supervisión educativa Revista de la Asociación de Inspectores de Educación de España, 18.
CANALS, R. (2011). La evaluación de la competencia social y ciudadana en la educación obligatoria. En P. MIRALLES MARTÍNEZ; S. MOLINA PUCHE y A. SANTISTEBAN FERNÁNDEZ (eds.), La evaluación en el proceso de enseñanza y aprendizaje de las ciencias sociales. Volumen I (143-154). Murcia: Asociación Universitaria de Profesorado de Didáctica de las Ciencias Sociales.

CANALS, R. (2013). Competencias básicas en Ciencias Sociales. Cuadernos de Pedagogía, 435, 26-28.

CARRETERO, M. y ASENSIO, M. (1988). La enseñanza de las ciencias sociales: aspectos cognitivos y psicopedagógicos. En F. HUARTE, (Coord.), Temas actuales sobre psicopedagogía y didáctica (205-221). Madrid: Narcea.

COLÁS, M. ${ }^{a}$ P., BUENDÍA, L. y HERNÁNDEZ, F. (2009). Competencias científicas para la realización de una tesis doctoral: guía metodológica de elaboración y presentación. Barcelona: Davinci.

COLL, C. (1993). Aprendizaje escolar y construcción del conocimiento. Buenos Aires: Paidós.

ESCAMILLA, A. (2011). Las competencias en la programación de aula. Vol. II Educación Secundaria (12-18 años). Barcelona: Graó.

GARCÍA, T. (2003). El cuestionario como instrumento de investigación/evaluación. Recuperado de http://www.uni- 
vsantana.com/sociologia/El_Cuestionario.pdf [15 de febrero 2013].

GÓMEZ, D. y MARTÍNEZ, J. M., (1997). La evaluación en Ciencias Sociales: la Historia Económica. Boletín del Instituto de Estudios Almerienses, 15, 133-146.

HERNÁNDEZ, V. M. (2005). Asesorando a centros educativos implicados en procesos de mejora escolar. Revista Electrónica Iberoamericana sobre Calidad, Eficacia y Cambio en Educación, 3 (1), 494-502.

LÓPEZ, R. (1997). La práctica de la evaluación aplicada al área de Ciencias Sociales en la enseñanza secundaria. En H. SALMERÓN (ed.), Evaluación educativa. Teoría, metodología y aplicaciones en áreas de conocimiento (371-397). Granada: Grupo Editorial Universitario, vol. 1.

MARTÍNEZ, M. ${ }^{a}$ E. (2008). La evaluación de Historia de España en COUy Bachillerato en la Comunidad Autónoma de la Región de Murcia (19932004). (Tesis doctoral inédita). Universidad de Murcia, Murcia.

MARTORELL I GELABERT, C. (2011). Inspecció educativa i formació permanent del professorat. Innov[IB]. Recursos i Recerca Educativa de les Illes Balears, 2, 127-139.

MERCHÁN, F. J. (2005). Enseñanza, examen y control: profesores y alumnos en la clase de historia. Barcelona: Octaedro.

MIRALLES, P., MOLINA, S. y SANTISTEBAN, A. (eds.) (2011). La eva- luación en el proceso de enseñanza y aprendizaje de las ciencias sociales. Murcia: AUPDCS.

MIRALLES, P., GÓMEZ, C. J. y MONTEAGUDO FERNÁNDEZ, J. (2012).

La evaluación de la competencias social y ciudadana en ciencias sociales al finalizar las etapas de Primaria y Secundaria. Investigación en la escuela, 78, 19-30.

MOLINA, S., ORTUÑO, J. y MIRALLES, P. (2011). El comentario de fuentes primarias como herramienta para la evaluación de competencias básicas en Historia. En P. MIRALLES, S. MOLINA y A. SANTISTEBAN (eds.), La evaluación en el proceso de enseñanza y aprendizaje de las ciencias sociales (295-306). Volumen I. Murcia: Asociación Universitaria de Profesorado de Didáctica de las Ciencias Sociales.

MONTEAGUDO, J., SÁNCHEZ, R., MOLINA, J. y MIRALLES, P. (2011). Estudio sobre los criterios e instrumentos de evaluación de la materia de Geografía en Educación Secundaria. En I. BARÇA (Ed.), Atas das XI Jornadas Internacionais de Educaçao Històrica. Consciência històrica na era da globalizaçao (527-538). Braga.

MONTEAGUDO, J. y VILLA, J. L. (2011). La evaluación de las competencias básicas en la materia de Historia en $4 .^{\circ}$ de ESO en la Región de Murcia. En P. MIRALLES, S. MOLINA y A. SANTISTEBAN (Eds.), $L a$ evaluación en el proceso de ense- 
ñanza y aprendizaje de las ciencias sociales. Volumen Investigador (317325). Murcia: Asociación Universitaria de Profesorado de Didáctica de las Ciencias Sociales.

NAVARRO, J. M. (2008). La práctica de investigación histórica como vía para iniciar el trabajo en competencias en ciencias sociales. Analizando las consecuencias de la Guerra de la Independencia en el marco local. Íber. Didáctica de las Ciencias Sociales. Geografía e Historia, 56, 53-62.

ORDANZA, F. El proceso de evaluación en ciencias sociales. Recuperado de http://www.medellin.edu.co/sites/ Educativo/Docentes/cienciassociales/Biblioteca/EL\%20PROCESO $\% 20$ DE $\% 20$ EVALUACION\%20EN $\% 20$ LAS\%20CIENCIAS\%20SOCIALES. pdf [29 de febrero de 2012]

ORTUÑO, J., GÓMEZ, C. J. y ORTIZ, E. (2012). La evaluación de la competencia educativa social y ciudadana desde la didáctica de las ciencias sociales. Un estado de la cuestión. Didáctica de las Ciencias Experimentales y Sociales, 26, 53-72. DOI: 10.7203/DCES.26.1931.

PAGÈS, J. (2007). Un itinerario por el mundo de las competencias en ciencias sociales, geografía e historia a través de distintos currículos. Íber. Didáctica de las Ciencias Sociales, Geografía e Historia, 52, 29-39.

PERRENOUD, PH. (2008). La evaluación de los alumnos. De la producción de la excelencia a la regulación de los aprendizajes. Entre dos lógicas. Buenos Aires: Colihue.

POLO, I. (2012). La evaluación objetiva del alumnado de Primaria y Secundaria. En Avances en supervisión educativa Revista de la Asociación de Inspectores de Educación de España, 16.

PRATS, J. (2011). ¿Por qué y para qué enseñar historia? En J. PRATS et al., Enseñanza y aprendizaje de la historia en la Educación Básica (1868). México: Universidad Pedagógica Nacional.

SANTOS, M.Á. (2003). Una flecha en la diana. La evaluación como aprendizaje. Madrid: Narcea.

SILVA, B. (2013). El papel de la inspección escolar en la mejora de los resultados educativos. Educar, 49 (1), 67-82.

TIANA, A. (2011). Análisis de las competencias básicas como núcleo curricular en la educación obligatoria española. Bordón. Revista de Pedagogía, 63 (1), 63-75.

TREPAT, C. A. (2012). La evaluación de los aprendizajes de historia y geografía en la enseñanza secundaria. Las pruebas de ensayo abierto. Íber. Didáctica de las Ciencias Sociales, Geografía e Historia, 70, 87-97.

TRIVIÑO, J. (2008). La evaluación en Educación Primaria. Innovación y experiencias educativas, 13.

VILLA, J. L. (2004). Contextos para el aprendizaje: estrategias para facilitar la comprensión y el desarro- 
llo de capacidades cognitivas en la enseñanza de la Geografía Humana. (Tesis doctoral). Madrid: Universidad Autónoma de Madrid.

VILLA, J. L. (2007). Contextos para el aprendizaje: papel de las estrategias instruccionales y de evaluación en el desarrollo de capacidades a partir del aprendizaje de la geografía. Madrid: Universidad Autónoma de Madrid.
VILLA, J. L. y ALONSO, J. (1996). ¿Cómo se evalúa el aprendizaje en enseñanzas medias? Revista de Ciencias de la Educación, 168, 473-503.

ZEMELMAN, S., DANIELS, H. y HYDE, A. (1998). Best Practice: New Standards forTeaching and Learning in America's Schools. Portsmouth, New Hampshire: Heineman. 